\title{
Profound Changes in Dopaminergic Neurotransmission in the Prefrontal Cortex in Response to Flattening of the Diurnal Glucocorticoid Rhythm: Implications for Bipolar Disorder
}

\author{
Gareth O Minton', Allan H Young', Richard McQuade', Graeme Fairchild ${ }^{3}$, Colin D Ingram' and \\ Sarah E Gartside ${ }^{1, *}$ \\ 'Psychobiology Research Group, Institute of Neuroscience, Newcastle University, Framlington Place, Newcastle upon Tyne, UK; ${ }^{2}$ Department of \\ Psychiatry, Institute of Mental Health, University of British Columbia, Vancouver, British Columbia, Canada; ${ }^{3}$ Developmental Psychiatry Section, \\ Department of Psychiatry, Cambridge University, Cambridge, UK
}

\begin{abstract}
Patients with bipolar disorder have abnormalities in glucocorticoid secretion, dopaminergic neurotransmission, and prefrontal cortical function. We hypothesized that the flattening of the diurnal glucocorticoid rhythm, commonly seen in bipolar disorder, modulates dopaminergic neurotransmission in the prefrontal cortex (PFC) leading to abnormalities in prefrontally mediated neurocognitive functions. To address this hypothesis, we investigated the effects of a flattened glucocorticoid rhythm on (i) the release of dopamine in the PFC and (ii) the transcription of genes in the ventral tegmental area (VTA) coding for proteins involved in presynaptic aspects of dopaminergic neurotransmission. Male rats were treated for 13-15 days with corticosterone ( $50 \mu \mathrm{g} / \mathrm{ml}$ in the drinking water) or vehicle ( $0.5 \%$ ethanol). Corticosterone treatment resulted in marked adrenal atrophy and flattening of the glucocorticoid rhythm as measured by repeated blood sampling. Animals treated with corticosterone showed markedly enhanced basal dopamine release in the PFC as measured by microdialysis in the presence of a dopamine reuptake inhibitor. Depolarization-evoked release was also enhanced, suggesting that the corticosterone effect on basal release did not result from an increase in the neuronal firing rate. Local blockade of terminal $D_{2}$ autoreceptors failed to normalize release to control values, suggesting that the enhanced release was not because of reduced autoreceptor sensitivity. In situ hybridization histochemistry showed that mRNAs coding tyrosine hydroxylase and the vesicular monoamine transporter 2 were elevated in the VTA of corticosterone-treated rats. Our data show that flattening of the glucocorticoid rhythm increases dopamine release in the PFC possibly as a result of increased synthesis and vesicular storage. This provides a mechanistic explanation for prefrontal dysfunction in bipolar and other affective disorders associated with glucocorticoid dysrhythmia. Neuropsychopharmacology (2009) 34, 2265-2274; doi:I 0. I038/npp.2009.53; published online 3 June 2009
\end{abstract}

Keywords: dopamine; ventral tegmental area; microdialysis; in situ hybridization histochemistry; HPA axis; corticosteroid; corticosterone

\section{INTRODUCTION}

There is now compelling evidence that dopaminergic dysfunction is an underlying pathophysiological feature of the affective disorders, and in particular bipolar disorder. One of the key strands of evidence is derived from the pharmacological data, collected over the last quarter of a century, detailing the effects of various drugs on mood and cognitive functions in healthy subjects and bipolar patients. Thus, direct and indirect dopamine receptor agonists have been shown to precipitate manic episodes in bipolar patients (Brook and Cookson, 1978; Gerner et al, 1976;

*Correspondence: Dr SE Gartside, Psychobiology Research Group, Newcastle University, The Medical School, Framlington Place, Newcastle upon Tyne, Tyne and Wear, NE2 4HH, UK. Tel: + 44 191 222 7633, Fax: + 44 191 222 5227, E-mail: sasha.gartside@ncl.ac.uk Received 19 December 2008; revised 20 April 2009; accepted 22 April 2009
Kemperman and Zwanikken, 1987; Van Kammen and Murphy, 1975; Vlissides et al, 1978), whereas antipsychotic drugs, which block $\mathrm{D}_{2}$ receptors (Kapur and Mamo, 2003; Wilson et al, 1998) have efficacy in stabilizing mood symptoms during manic and depressive bipolar episodes (Brambilla et al, 2003; Surja et al, 2006; Wijkstra et al, 2006). More recently, it has been shown that depletion of the dopamine precursor tyrosine in bipolar subjects can reduce the symptoms of mania (McTavish et al, 2001) and, in healthy subjects, can induce disrupted affect/reward characteristics, which parallel those seen in bipolar depression (McLean et al, 2004).

The prefrontal cortex (PFC) is associated with working memory and executive functions (Dalley et al, 2004) and, more recently, has been implicated in emotional regulation through sub-cortical afferents (Beauregard et al, 2001; Levesque et al, 2003; Morgan et al, 2003; Ochsner et al, 2004; Ohira et al, 2006; Urry et al, 2006). Deficits in PFC- 
mediated working memory and executive functions, in addition to the cardinal symptoms of emotional dysregulation, are characteristic of patients with both bipolar and unipolar affective disorders (DeBattista, 2005; Kaiser et al, 2003; Kolur et al, 2006; Lampe et al, 2004; Malhi et al, 2007; Martinez-Aran et al, 2004; Porter et al, 2007; Quraishi and Frangou, 2002; Savitz et al, 2005; Thompson et al, 2005). Furthermore, imaging studies have revealed abnormalities in PFC biochemistry and function in patients with bipolar disorder (Blumberg et al, 2003; Robinson et al, 2008).

The PFC receives inputs from the ventral tegmental area (VTA) through the mesocortical dopaminergic projection system. Dopaminergic neurotransmission in the PFC has a complex modulatory influence on mnemonic and executive functions mediated by this region (Arnsten, 1997; Floresco and Magyar, 2006; Mizoguchi et al, 2004; Robbins, 2005), in addition to regulating the emotional aspects of PFC function (Fernandez Espejo, 2003; Morrow et al, 1999). In the context of the PFC functional deficits characteristic of bipolar patients, these data suggest a potential role for prefrontal dopaminergic dysfunction in the pathophysiology of bipolar disorder.

Clinical studies have shown that a common feature of affective disorders is disruption to the diurnal pattern of hypothalamic-pituitary-adrenal (HPA) axis activation. This disruption, which takes the form of an elevated basal plasma cortisol level, and a flattening of the diurnal rhythm, is particularly evident in severe/psychotic unipolar depression and bipolar disorder (Akesode et al, 1976; Cervantes et al, 2001; Deuschle et al, 1997; Linkowski et al, 1994; Sachar, 1975; Yehuda et al, 1996). Glucocorticoids have been linked to dopaminergic abnormalities in severe affective disorders (Schatzberg et al, 1985) on the basis of evidence that dopamine neurotransmission can be regulated by glucocorticoids. For example, in rats, adrenalectomy decreases dopaminergic neurotransmission in terminal projection regions (Barrot et al, 2001; Barrot et al, 2000; Biron et al, 1992; Faunt and Crocker, 1988, 1989; Mizoguchi et al, 2004; Piazza et al, 1996; Shoaib and Shippenberg, 1996; Tanganelli et al, 1990), whereas there is some evidence that chronic high-dose corticosterone increases dopaminergic function (Czyrak et al, 2003). Although manipulations such as those used in the above studies establish the principle that dopaminergic function is glucocorticoid sensitive, they do not necessarily predict the consequences of the subtle glucocorticoid dysregulation seen in affective disorders. Hence, the hypothesis that glucocorticoid dysrhythmia is causative in the development of mesocortical dopamine dysfunction in mood disorders (and particularly bipolar disorder) remains untested.

Here, we determined the effect of a subtle elevation and flattening of the diurnal glucocorticoid rhythm on various functional aspects of the rat mesocortical dopaminergic system. Using a treatment protocol validated by repeated blood sampling, rats were administered a modest dose of corticosterone in their drinking water, over a 2-week period, to flatten the glucocorticoid rhythm. We employed in vivo microdialysis to measure basal and stimulated dopamine levels in the PFC, and in situ hybridization histochemistry with autoradiography to determine the expression of mRNAs coding for a variety of proteins involved in the synthesis, release, reuptake, and metabolism of dopamine.

\section{METHODS}

\section{Drugs and Chemicals}

Corticosterone (Sigma, Poole, Dorset, UK) was dissolved in ethanol (Fischer Scientific, Loughborough, Leicestershire, UK). Bupropion (Sigma) and sulpiride (Sigma) were dissolved in aCSF. Urethane (Sigma) was dissolved in water for injection. All other chemicals were of analytical or high laboratory grade.

\section{Animals and Corticosterone Treatment}

Male Lister hooded rats (Charles River, Margate, Kent, UK), housed in groups of four, were used throughout.

\section{Validation of Corticosterone Treatment Protocol}

Two groups of animals were prepared for continuous blood sampling to monitor the effects of corticosterone and vehicle treatment regimes on the diurnal corticosterone rhythm. All animals underwent 'sham surgery' for a corticosterone treatment protocol involving implanted pellets (data not reported here). This involved a small skin incision and suturing under general anesthesia with isoflurane. The procedure took only a few minutes and animals were returned to group housing afterwards. Beginning the day after surgery, animals were treated with corticosterone $(50 \mu \mathrm{g} / \mathrm{ml})$ in the drinking water, or vehicle $(0.5 \%$ ethanol $)$ in drinking water. Animals had ad lib access to the drinking water.

Blood sampling and hormone assays were conducted as described elsewhere (Windle et al, 1998). Briefly, on the tenth day of treatment animals were anaesthetized and the jugular vein was cannulated, with the cannula exteriorized and attached to a steel spring screwed to the skull. After cannulation, animals were singly housed and 4 days later (day 14 of treatment) cannulae were connected to a blood sampling system. Samples of whole blood $(20 \mu$ liluted in $100 \mu \mathrm{l}$ heparinised saline) were collected every $20 \mathrm{~min}$ over more than $24 \mathrm{~h}$. Samples were pooled for corticosterone analysis by radioimmunoassay.

\section{Measures of Dopaminergic Function}

All animals were treated for between 13 and 15 days with corticosterone or vehicle in their drinking water as described above. The volume of water consumed by each cage of animals was recorded and animals were weighed regularly to monitor their health. Note: these animals did not undergo sham surgery or surgery for cannulation.

\section{In Vivo Microdialysis}

After corticosterone $(n=12)$ or vehicle $(n=12)$ treatment for 13-15 days, animals were anaesthetized with urethane $(1500 \mathrm{mg} / \mathrm{kg})$ and fixed in a stereotaxic frame (David Kopf, Tujunga, CA, USA) in the flat skull position. A concentric microdialysis probe $(40 \mathrm{~mm}$ dialysing window; AN69 Hospal membrane, Gambro Hospal Ltd, Huntingdon, Cambridgeshire) was stereotaxically implanted in the PFC $(3.0 \mathrm{~mm}$ rostral and $0.7 \mathrm{~mm}$ lateral of bregma and $-5.5 \mathrm{~mm}$ below the dura surface). The probe was perfused with 
artificial cerebrospinal fluid (termed 'standard aCSF') (composition: $140 \mathrm{mM} \mathrm{NaCl} ; 3 \mathrm{mM} \mathrm{KCl} ; 1 \mathrm{mM} \mathrm{MgCl}_{2}$; $1.2 \mathrm{mM} \mathrm{NaHPO}$; $0.27 \mathrm{mM} \mathrm{NaH} \mathrm{PO}_{4} ; 7.2 \mathrm{mM}$ glucose; and $2.4 \mathrm{mM} \mathrm{CaCl} 2)$ containing bupropion $(30 \mu \mathrm{M})$ at a flow rate of $1 \mathrm{ml} / \mathrm{min}$. Dialysate samples were collected every $20 \mathrm{~min}$ and dopamine content was measured using HPLC with electrochemical detection (Coulochem II, ESA Analytical, Aylesbury, Buckinghamshire, UK; Cell $1+100 \mathrm{mV}$; Cell $2+$ $350 \mathrm{mV})$. Mobile phase for HPLC comprised $83 \mathrm{mM}$ $\mathrm{NaH}_{2} \mathrm{PO}_{4}, 0.84 \mathrm{mM}$ EDTA, $0.46 \mathrm{mM}$ OSA, $15 \%$ methanol in deionised water, $\mathrm{pH}=4.0$.

Once a steady baseline of dopamine, of at least $60 \mathrm{~min}$ duration, was obtained with standard aCSF, depolarizationevoked release was induced by switching the perfusion for 'high $\mathrm{K}^{+}$aCSF', which contain $100 \mathrm{mM} \mathrm{K}^{+}$, for a period of $20 \mathrm{~min}$. Then, after a further $60-100 \mathrm{~min}$ perfusion of standard aCSF, the perfusion was switched to 'sulpiride aCSF', which contained the $\mathrm{D}_{2 / 3}$ receptor antagonist sulpiride $(10 \mu \mathrm{M})$ for $80 \mathrm{~min}$, followed by 'high $\mathrm{K}^{+} /$sulpiride aCSF', which contained both $100 \mathrm{mM} \mathrm{K}^{+}$and sulpiride $(10 \mu \mathrm{M})$ for $20 \mathrm{~min}$. Finally, the perfusion was again switched to sulpiride aCSF. Note: all aCSF contained bupropion $(30 \mu \mathrm{M})$.

At the end of the experiment, animals were killed by anesthetic overdose and one adrenal gland was removed and weighed.

\section{Tissue Collection and Sectioning for In Situ Hybridization Histochemistry}

Two groups of animals ( $n=8$ per group) were treated for 14 days with corticosterone or vehicle as described earlier. At the end of treatment, animals were killed by overdose with sodium pentobarbital $(0.7 \mathrm{ml} / \mathrm{kg}$ i.p., $20 \% \mathrm{w} / \mathrm{v}$ solution, Dolethal, Vetoquinol, Buckingham, Buckinghamshire, UK). Note: all animals used for in situ hybridization histochemistry had received the DOPA decarboxylase inhibitor NSD1015 (100 mg/kg i.p.) $20 \mathrm{~min}$ before killing to allow analysis of tyrosine hydroxylase (TH) activity (data not reported here). After killing, the brain was removed, divided coronally, and the portion containing the midbrain was snap frozen in isopentane on dry ice. In a subset of these animals ( $n=4$ per group) one adrenal gland was removed, dissected from surrounding tissue, and weighed.

Brain tissue was stored at $-80^{\circ} \mathrm{C}$ before sectioning. Sections $(12 \mu \mathrm{m}$ thick) were cut on a cryostat and thaw mounted onto RNAase-free gelatin-subbed slides. Adjacent sections were mounted across a series of slides; four sections per slide were collected. Mounted sections were stored frozen at $-80^{\circ} \mathrm{C}$ until pretreatment. Sections were fixed in $4 \%$ paraformaldehyde, acetylated in $0.25 \%$ acetic anhydride, defatted in chloroform and dehydrated in ethanol before being air-dried and stored at $-20^{\circ} \mathrm{C}$.

\section{In Situ Hybridization Histochemistry}

Oligonucleotide probes were synthesized by MWG-Biotech AG (Ebersberg, Germany). Sequences were as follows:

TH: 36 base probe sequence complimentary to bases 1380-1415 of the rat TH gene (L22651 (Anton et al, 1994)): 5'-GGG AGA ACT GGG CAA ATG TGC GGT CAG CCA ACA TGG-3'; vesicular monoamine transporter 2 (VMAT2): 48 base probe sequence complimentary to bases $271-318$ of the rat VMAT2 gene (NM 013031 (Schwartz et al, 2003)): 5' ATG CCT TTA GGT CTG GTG GTC TGG TCT CGA GCA CCA GAG GTG GAG GCT-3'; dopamine transporter (DAT): 43 base probe sequence complimentary to bases 1015-1057 of the rat DAT gene (M80233 (Kilty et al, 1991)): 5'-GAG AAG GCA ATC AGC ACT CCA AAC CCA ACG CCG AGG GAG AAG C-3'; monoamine oxidase A $\left(\mathrm{MAO}_{\mathrm{A}}\right): 36$ base probe sequence complimentary to bases $1591-1626$ of the MAO-A gene (XM_001058993): 5'-AAG ATA CGC AAA TTC CCG AGC AGT TTT TGT CCA ACA-3'; $\mathrm{D}_{2}$ receptor: 36 base probe sequence complimentary to bases $787-820$ of the rat $\mathrm{D}_{2}$ receptor gene (X17458 (Monsma et al, 1989)): 5'-GTG TTG ACC CGC TTC CGG CAC TTC CGG AGG ACG AGT- $3^{\prime}$.

Probes were labelled with ${ }^{35} \mathrm{~S}$-dATP at the $3^{\prime}$-end using terminal deoxynucleotidyl transferase (TDT) enzyme (Roche Diagnostics, Burgess Hill, West Sussex, UK). Radiolabelled probe and unbound ${ }^{35} \mathrm{~S}$ were separated using Sephadex columns. Tissue sections (one slide from each animal, three sections per slide) were incubated with $\sim 200 \mu \mathrm{l}$ radiolabelled probe $(70000-100000$ c.p.m./ $\mu \mathrm{l})$ in hybridization buffer. The hybridization buffer comprised of the following: $50 \%$ formamide; $4 \times$ saline sodium citrate (SSC); $25 \mathrm{mM}$ phosphate buffer; $10 \mathrm{mM}$ sodium pyrophosphate; $5 \times$ Denhardt's solution; $200 \mu \mathrm{g} / \mathrm{ml}$ denatured Salmon sperm DNA; $100 \mu \mathrm{g} / \mathrm{ml}$ polyadenosine $5 \mathrm{mg} / \mathrm{ml}$; $120 \mu \mathrm{g} / \mathrm{ml}$ heparin; $10 \%$ dextran sulphate; and $50 \mathrm{mM}$ dithiothreitol. After overnight incubation, slides were washed $(1 \times$ SCC room temperature $20 \mathrm{~min} ; 1 \times$ SSC $55^{\circ} \mathrm{C} 20 \mathrm{~min}$, twice; $1 \times$ SSC room temperature $1 \mathrm{~h}$ ) and allowed to air dry. Slides were then exposed to MR Biomax film (Amersham Biosciences, Little Chalfont, Buckinghamshire, UK). A slide containing a ${ }^{14} \mathrm{C}$ microscale (Amersham Biosciences) standard was included for the purpose of calibration. Films were developed 2-4 weeks later using an automatic developer (Agfa Curix Daylight Processor) and analyzed.

\section{Densitometry}

The TH mRNA signal was used to ensure alignment of the sections between animals such that measurements could be made at a consistent rostrocaudal level of the VTA. Optical densitometry was used to measure mRNA expression. Mean optical density across the VTA, measured on left and right sides of a single section, was converted to $\mathrm{nCi} / \mathrm{g}$ of brain tissue using a calibration curve based on the ${ }^{14} \mathrm{C}$ standard microscale (Amersham Biosciences). Values were then averaged between the left and right sides of the brain.

\section{Data Analysis and Statistics}

Repeated blood sampling data are presented as averages over $3 \mathrm{~h}$ blocks starting and finishing at 1100 hours. Data were analyzed by two-way repeated measures ANOVA with post hoc $t$-test.

For statistical analysis, microdialysis data were reduced to four measures. Basal levels refers to the average of the three samples before the first $\mathrm{K}^{+}$stimulation; $\mathrm{K} 1$ refers to the peak dopamine concentration measured in the dialysate collected during the first 20 min perfusion with high $\mathrm{K}^{+}$ aCSF; sulpiride response refers to the average of three samples taken during the administration of sulpiride $(10 \mu \mathrm{M}) ; \mathrm{K} 2$ refers to the peak dopamine concentration 
measured in the dialysate collected during the second $\mathrm{K}^{+}$ stimulation (ie, in the presence of sulpiride $(10 \mu \mathrm{M})$ ).

Student's paired $t$-test was used to determine the significance of treatment effects on basal levels and K1. The impact of treatment on the sulpiride response was analyzed by two-way ANOVA with repeated measures comparing sulpiride response with basal levels in the two treatment groups. The effect of treatments on K2 was analyzed using two-way ANOVA with repeated measures comparing $\mathrm{K} 2$ with $\mathrm{K} 1$ in the two treatment groups.

For the in situ hybridization histochemistry data, comparison of mRNA expression between treatment groups was performed using Student's unpaired $t$-test.

Data are presented as mean \pm SEM (n). Significance at the $95 \%$ level is quoted.

\section{RESULTS}

\section{Corticosterone Treatment}

Animals appeared healthy throughout the treatment. Weight gain and final weight did not differ between treatment groups. Corticosterone-treated animals drank around $32 \mathrm{ml}$ water/day giving them an approximate dose of $5.8 \mathrm{mg} / \mathrm{kg} /$ day. Water consumption per cage did not differ significantly between treatment groups.

Blood corticosterone concentrations in the vehicle-treated animals showed a clear diurnal rhythm, being highest around the time of lights off (1900 hours) and lowest around the time of lights on (see Figure 1). In animals treated with corticosterone in their drinking water, there was also a diurnal rhythm but it was flattened compared with the vehicle-treated animals with the peak being slightly reduced and the nadir markedly raised. Statistical analysis

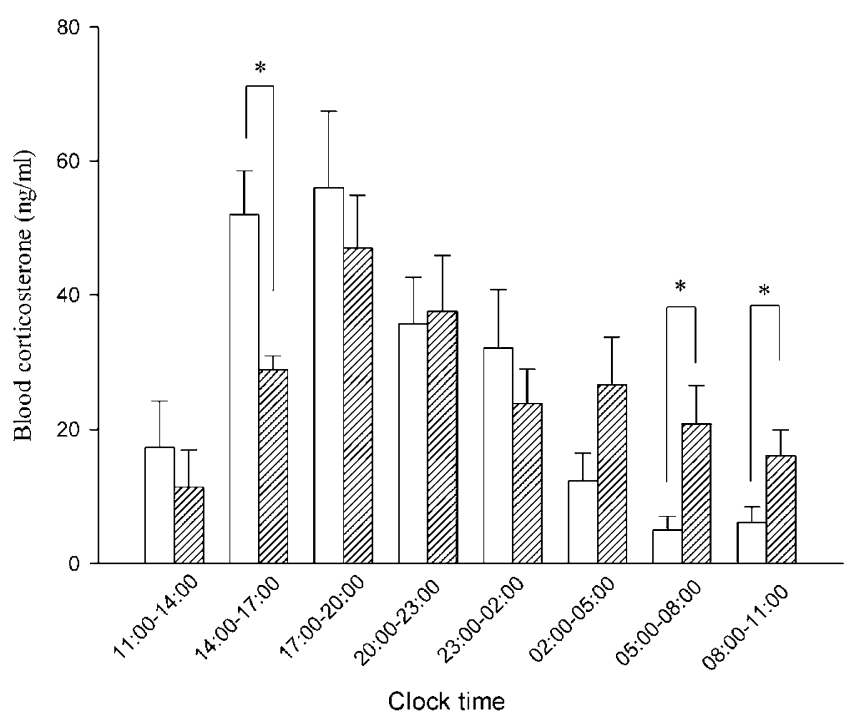

Figure I Effect of corticosterone administration on the $24 \mathrm{~h}$ blood corticosterone profile. Blood corticosterone levels averaged in $3 \mathrm{~h}$ blocks in rats treated for 14 days with corticosterone $(50 \mu \mathrm{g} / \mathrm{ml})$ or vehicle $(0.5 \%$ ethanol) in the drinking water. Data are mean \pm SEM ( $n=6$ (vehicle) and 8 (corticosterone)). Bar represents the period of darkness. $* p<0.05$ unpaired $t$-test after significant two-way ANOVA. See text for full statistical analysis. of these data showed a significant main effect of time $\left(\mathrm{F}_{7,84}=12.1 ; p<0.0001\right)$ and no significant main effect of treatment but a significant time $\times$ treatment interaction $\left(\mathrm{F}_{7,84}=2.5 ; p<0.05\right)$. Post hoc $t$-tests showed that corticosterone levels in the treated animals were significantly lower in the sample before the diurnal peak (1400-1700 hours), and significantly higher in the two samples at the nadir of the rhythm (0500-0800 and 0800-1100 hours).

In the microdialysis and in situ hybridization histochemistry studies, the corticosterone treatment was monitored by measuring adrenal gland weight as this has been shown earlier to be reduced by this corticosterone-treatment protocol (Fairchild et al, 2003). Corticosterone treatment significantly reduced adrenal gland weight in both the experimental groups. Thus, in the microdialysis study, the adrenal: body weight ratio was $12.2 \times 10^{-5} \pm 0.40 \times 10^{-5}$ $(n=12)$ and $6.8 \times 10^{-5} \pm 0.37 \times 10^{-5}(n=12)$ in the vehicleand corticosterone-treated groups, respectively $(p<0.0001$ unpaired $t$-test). In the in situ hybridization histochemistry study, the adrenal:body weight ratio was $10.5 \times 10^{-5} \pm 0.31 \times 10^{-5} \quad(n=4)$ and $5.2 \times 10^{-5} \pm 0.84 \times$ $10^{-5}(n=4)$ in the vehicle- and corticosterone-treated groups, respectively ( $p<0.005$ unpaired $t$-test).

\section{Microdialysis Studies: Effect of Corticosterone Treatment on Basal and Depolarization-Evoked Dopamine Release}

Basal dopamine levels measured during perfusion of standard aCSF were markedly and significantly elevated in corticosterone-treated animals in comparison with vehicletreated controls $(p<0.01)$ (see Figures 2 and 3a). Perfusion of high $\mathrm{K}^{+}$aCSF evoked an increase in dialysate dopamine in both treatment groups (Figure 2). However, K1 was

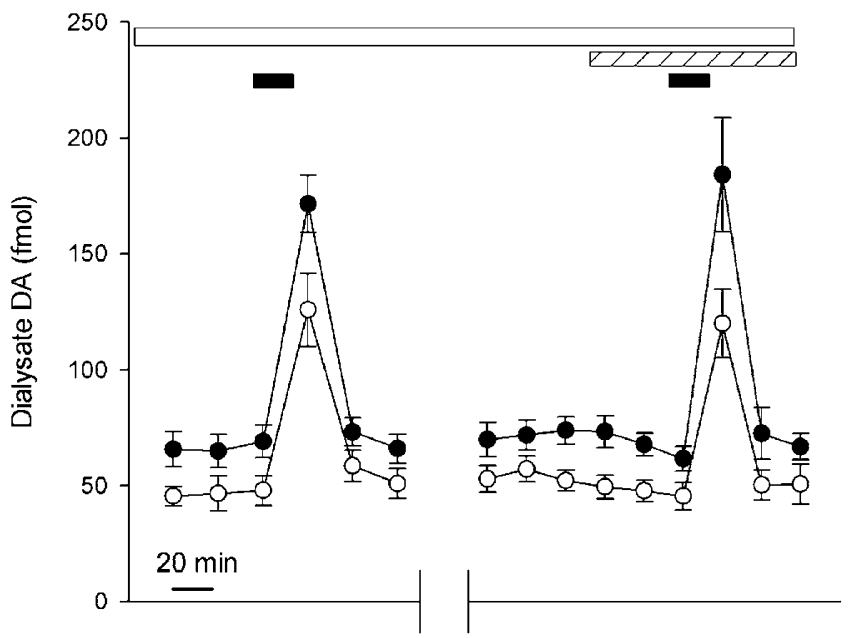

Figure 2 Effect of corticosterone treatment on basal dialysate dopamine. Time course of changes in dialysate levels of DA in the vehicle-treated (open circles) and corticosterone-treated (closed circles) groups. Data are mean \pm SEM. Only animals for which the whole timecourse data set was available are included in this figure $(n=6$ and 7 per group). Bars indicate the application of aCSF solutions of different compositions through the dialysis probe. Open bar indicates aCSF containing bupropion $(30 \mu \mathrm{M})$, hatched bar indicates aCSF containing sulpiride $(10 \mu \mathrm{M})$, filled bars indicate aCSF with $100 \mathrm{mM} \mathrm{K}{ }^{+}$. See Figures 2 and 3 and Results section for statistical analysis. 
significantly greater in the corticosterone-treated group than the vehicle-treated group $(p<0.01)$ (Figure 3a).

\section{Microdialysis Studies: Effect of Corticosterone Treatment on $\mathrm{D}_{2}$ Receptor-Mediated Autoinhibition of Dopamine Release}

The local perfusion of sulpiride, a $\mathrm{D}_{2 / 3}$ receptor antagonist, caused a small decrease in dopamine levels (see Figure 2),
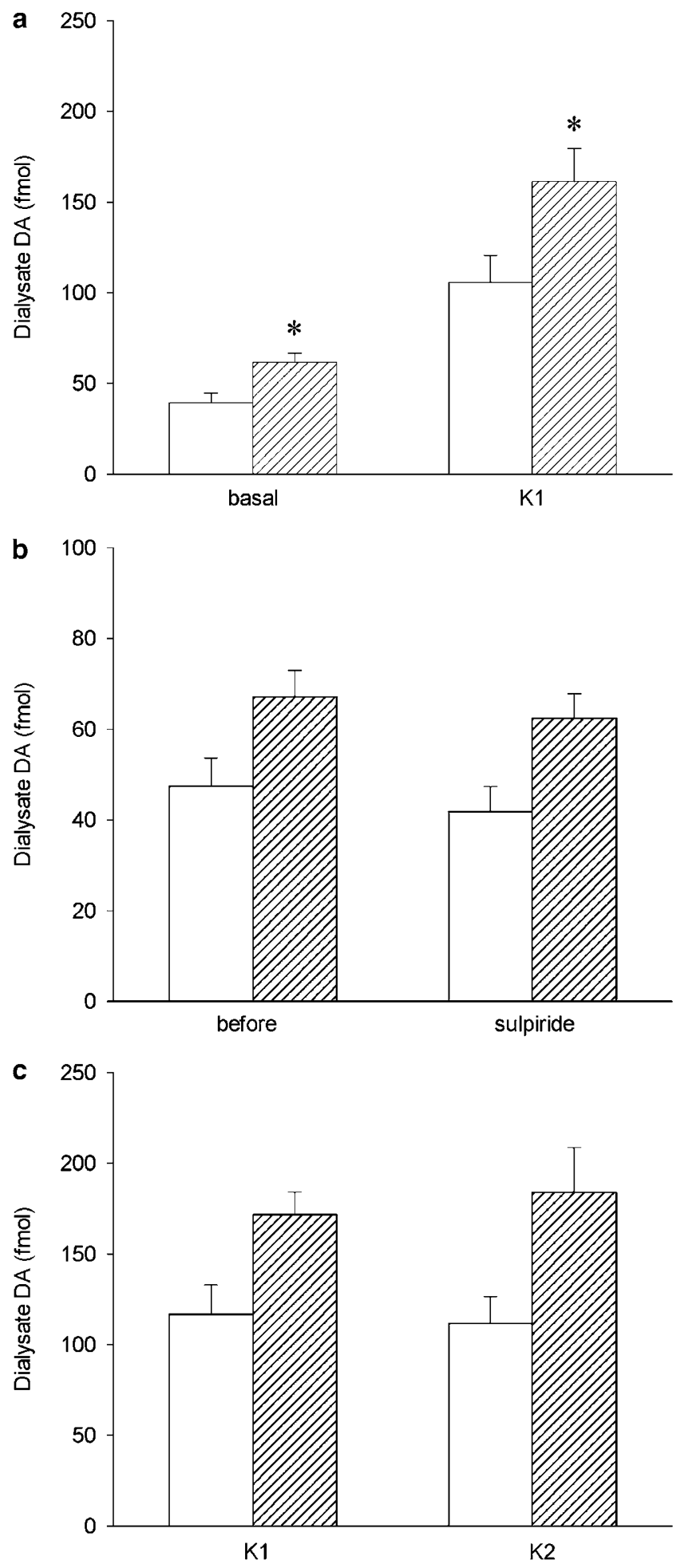

which did not reach significance in either treatment group. Thus, two-way ANOVA with repeated measures showed a significant main effect of corticosterone treatment $\left(\mathrm{F}_{1,13}=9.5, p<0.01\right)$, but no significant main effect of sulpiride $\left(\mathrm{F}_{1,13}=3.1, \mathrm{NS}\right)$, and no significant treatment $\times$ sulpiride interaction $\left(\mathrm{F}_{1,13}=0.2\right.$, NS) (Figure $3 \mathrm{~b}$ ). Sulpiride also failed to influence the depolarization-evoked dopamine release in either treatment group, such that the effect of corticosterone treatment on evoked dopamine release was maintained in the presence of sulpiride (Figure 2). Two-way repeated measures ANOVA, comparing $\mathrm{K} 1$ and $\mathrm{K} 2$ in the two treatment groups, showed a significant effect of corticosterone $\left(\mathrm{F}_{1,12}=7.9, p<0.02\right)$, but no significant effect of sulpiride $\left(\mathrm{F}_{1,12}=1.3\right.$, NS $)$ and no significant interaction between the two factors $\left(\mathrm{F}_{1,12}=0.7\right.$, NS) (Figure 3c).

\section{Effect of Corticosterone Treatment on The Expression of mRNAs Coding for Proteins Regulating Presynaptic Dopamine Function}

The mRNAs coding for TH, VMAT2, DAT, $\mathrm{D}_{2}$, and $\mathrm{MAO}_{\mathrm{A}}$ were densely expressed in the VTA and adjacent dopaminergic cells groups such as the substantia nigra (Figure 4). In our coronal midbrain sections, $\mathrm{TH}, \mathrm{DAT}$, and $\mathrm{D}_{2} \mathrm{mRNA}$ expression was not seen outside of these regions; VMAT2 and $\mathrm{MAO}_{\mathrm{A}}$ were lightly expressed in the hippocampus and cortex.

In the VTA, the expression of mRNAs coding for both TH and VMAT2 was significantly higher in corticosteronetreated animals than in controls $(p<0.05)$ (Figure 5). The expression of $\mathrm{D}_{2}$ receptor mRNA was also significantly increased in corticosterone-treated animals, although the magnitude of the effect was small. In contrast, corticosterone treatment had no significant effect on the expression of mRNAs coding for DAT or $\mathrm{MAO}_{\mathrm{A}}$ in the VTA (Figure 5).

\section{DISCUSSION}

In this study, we used a paradigm of corticosterone treatment in rats, which mimicked the flattened and elevated glucocorticoid rhythm seen in patients with affective disorders including bipolar disorder. We have earlier shown that this corticosterone treatment protocol, in which animals are allowed free access to corticosterone in

Figure 3 Effect of corticosterone treatment on dopamine in dialysates of the prefrontal cortex. (a) Shows the effect of corticosterone treatment on basal and depolarisation-evoked dopamine. 'Basal' is the average of the three baseline samples and ' $\mathrm{KI}$ ' is the dopamine level in the dialysate collected during the perfusion of $100 \mathrm{mM} \mathrm{K} \mathrm{K}^{+}$. ${ }^{*} p<0.01$ paired $t$-test corticosterone vs vehicle. (b) Shows the effect of corticosterone treatment on the response to sulpiride. 'Before' is the average of three samples before perfusion of sulpiride and 'sulpiride' is to an average of the three samples collected during perfusion of sulpiride. (c) Shows the effect of corticosterone on depolarisation-evoked DA levels in the absence and presence of sulpiride. ' $\mathrm{KI}$ ' is the peak level during the perfusion of $\mathrm{K}^{+}$ $100 \mathrm{mM}$ in the absence of sulpiride and ' $\mathrm{K} 2$ ' is the peak DA level during the perfusion of $\mathrm{K}^{+} 100 \mathrm{mM}$ in the presence of sulpiride $(10 \mu \mathrm{M})$. Data from the vehicle group is shown in the open bars, the corticosterone-treated group is shown in the hatched bars. Data are mean \pm SEM. (a) $n=11$ and 12 per group, (b) $n=8$ and 9 per group, (c) $n=7$ and 7 per group. See Results section for full statistical analysis. 

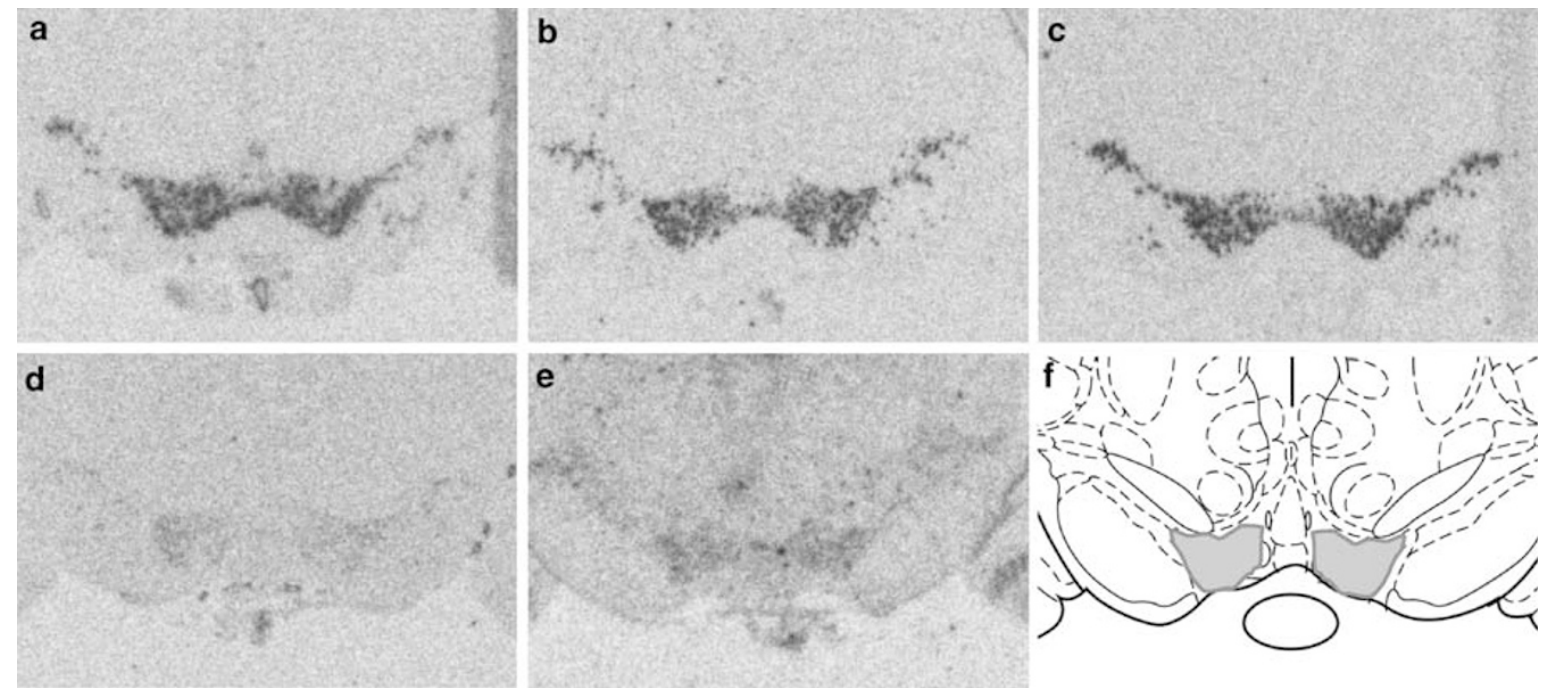

Figure 4 Expression of selected mRNA species in the VTA. Sample autoradiograms from coronal sections of midbrain (from vehicle-treated animals) showing the typical observed distribution of expression of mRNAs encoding (a) tyrosine hydroxylase (TH), (b)VMAT2, (c) D 2 receptor, (d) dopamine transporter (DAT), and (e) monoamine oxidase $\mathrm{A}\left(\mathrm{MAO}_{\mathrm{A}}\right)$; (f) shows a plate from the Rat Brain Atlas (Paxinos and Watson, 1986) at the corresponding level with the VTA shaded in grey.

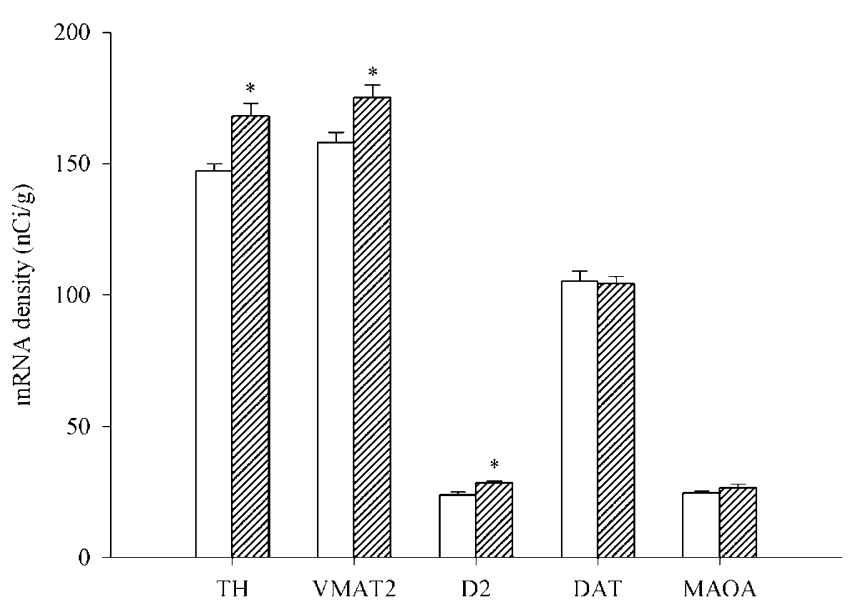

Figure 5 Expression of mRNA species in the VTA. Expression of mRNAs encoding tyrosine hydroxylase $(T H)$, VMAT2, the $D_{2}$ receptor, dopamine transporter (DAT), and monoamine oxidase $A\left(M A O_{A}\right)$ in the VTA in vehicle-treated (open bars) and corticosterone-treated (hatched bars) groups. Data are mean \pm SEM ( $n=8 /$ group). * $p<0.01$ unpaired $t$-test.

their drinking water, elevates plasma corticosterone levels measured at a single time point close to the anticipated nadir and results in an approximate halving of adrenal weight (Fairchild et al, 2003). This effect on adrenal weight was confirmed in the animals used for microdialysis and in situ hybridization histochemistry. Furthermore, we used repeated blood sampling over $24 \mathrm{~h}$ and confirmed that the treatment protocol flattens the diurnal rhythm (ie, reduces the amplitude of the rhythm), principally by raising corticosterone levels at the nadir. We observed that, relative to controls, blood concentrations of corticosterone were increased at the end of the dark phase and at the beginning of the light phase and slightly reduced at the end of the light phase. This profile can be explained by the combination of exogenous and endogenous corticosterone. Thus, the intake of exogenous corticosterone, which occurs mainly during the dark phase when rats drink (Stephan and Zucker, 1972) has the effect of elevating (exogenous) corticosterone levels during this time period and extending into the early part of the light phase. However, the elevated levels in the light phase also tend to suppress the anticipated rise of endogenous corticosterone secretion at the end of the light phase, so resulting in reduced corticosterone levels at this time. It is worth noting that because of poor aqueous solubility the corticosterone was dissolved in ethanol. Although ethanol has been shown to alter aspects of dopamine function, albeit at much higher doses than used here (Ortiz et al, 1995b), this potential confounding was controlled for by adding ethanol to the drinking water of the control group.

Flattening of the glucocorticoid rhythm led to marked increases in both the basal dopamine release (ie, the level measured in the presence of bupropion) and depolarization-evoked release. We hypothesized that the observed changes in dopaminergic function were the result of transcriptional modulation of key dopaminergic regulatory components within the VTA. Accordingly, our in situ hybridization studies showed increases in the expression of mRNAs coding for TH, VMAT2, and $\mathrm{D}_{2}$ in the VTA. Although we must acknowledge that attributing functional alterations to changes at the transcriptional level is not straightforward, we can speculate on the most likely mechanism for the functional changes observed.

One possibility is that the corticosterone-treated animals had a lower rate of dopamine clearance. However, DAT (the main mechanism of clearance) was continuously blocked by perfusion of the dopamine uptake blocker bupropion, at a concentration shown to maximally inhibit uptake in the nucleus accumbens (Ferrie, 2004). This means that, we can discount the possibility of changes in DAT activity underlying the difference in dopamine dialysate levels. Further support is provided by our in situ data, which showed no effect of corticosterone treatment on DAT mRNA transcription. The use of bupropion throughout our experiment also means that we can regard changes in dialysate dopamine levels as indicative of changes in dopamine release. 
A second possibility is that an increase in the basal firing rate of mesocortical dopamine neurones led to an increase in dopamine release. However, the fact that corticosterone treatment resulted in an elevation of depolarization-evoked (as well as basal) dopamine release, suggests that this is not the case, as depolarization-evoked neurotransmitter release is not firing rate dependent.

A third potential mechanism involves a decrease in terminal autoreceptor-mediated inhibition of dopamine release. However, we found that the $\mathrm{D}_{2 / 3}$ receptor antagonist sulpiride failed to equalize basal or depolarization-evoked dopamine release between the two treatment groups. Indeed, in the control group, we found a (non-significant) decline in dopamine levels during sulpiride perfusion rather than the expected increase. These data indicate that there is little or no tonic activation of terminal $\mathrm{D}_{2 / 3}$ autoreceptors in the PFC during basal or depolarisation-evoked release. Several earlier studies support our data in this respect (Ago et al, 2005; Devoto et al, 2001; Gessa et al, 2000; Moghaddam and Bunney, 1990); but see (Bean and Roth, 1991). Our mRNA data also argue against a decrease in autoreceptor-mediated inhibition as we found an increase in $\mathrm{D}_{2}$ receptor gene transcription in the VTA of corticosterone-treated animals.

The most credible theory to explain our microdialysis findings involves a corticosterone-induced increase in the vesicular dopamine content. Our in situ data show that corticosterone administration increased gene transcription of both the dopamine synthetic enzyme, $\mathrm{TH}$, and the vesicular monoamine transporter, VMAT2. These data are supported by a number of studies showing corticosterone regulation of TH mRNA in the brain (Czyrak et al, 2003), the adrenal medulla and pheochromocytoma cell lines (Baetge et al, 1981; Kumai et al, 2000; Tank et al, 1986). Increases in TH protein expression have also been shown in the VTA after corticosterone administration. Interestingly, other groups have found that rat strains, which differ in with respect to their HPA axis activity and reactivity, also differ with respect to basal levels of TH in the VTA (Brodkin et al, 1999; Serova et al, 1998), as well as in the responsiveness of $\mathrm{TH}$ to administration of corticosterone (Haile et al, 2001; Ortiz et al, 1995a). The presence of a glucocorticoid response element (GRE) on the TH gene (Hagerty et al, 2001) suggests that glucocorticoids modulate TH mRNA transcription directly. Although the effect of glucocorticoids on VMAT2 mRNA expression has not been examined earlier, chronic stress has been shown to increase VMAT2 mRNA in medullary noradrenergic cell groups, (Rusnak et al, 2001) but to reduce VMAT2 binding in the nucleus accumbens and striatum (Zucker et al, 2005). It is possible that this latter finding represents a functional difference between mesolimbic and mesocortical dopamine systems.

Our hypothesis is that an increase in TH protein, and therefore dopamine synthesis, augments cytosolic dopamine concentrations, increasing the concentration gradient across the vesicular membrane and favouring vesicular accumulation of dopamine. In parallel, an increase in VMAT2 protein promotes active vesicular uptake of dopamine, further increasing vesicular dopamine content. Earlier studies have shown that increasing VMAT2 expression increases the amount of dopamine released per depolarisation event; this effect was attributed to an increase in vesicular dopamine content and not an increase in the number of vesicles undergoing exocytosis (Pothos et al, 2000). Our data are consistent with such a mechanism, as depolarisation-evoked stimulation produced the same percentage increase over basal dopamine levels in the corticosterone-treated and control groups, suggesting that exocytotic release mechanisms were unaltered. The evidence therefore suggests that increased vesicular content is a likely candidate to explain the increase in dopamine release seen in animals with a flattened glucocorticoid rhythm.

As discussed in the Introduction section, mood disorders are associated with a flattening of the diurnal glucocorticoid rhythm and an increase in circulating glucocorticoid (cortisol) levels during the daily nadir (Deuschle et al, 1997; Wong et al, 2000). This glucocorticoid dysrhythmia has also been observed in bipolar disorder patients (Cervantes et al, 2001; Linkowski, 2003). Our findings of marked alterations in aspects of dopaminergic neurotransmission suggest that the same alterations may occur in patients with bipolar disorder, and other affective disorders associated with a flattened glucocorticoid rhythm. In this respect, it is of note that clinical post-mortem brain studies have shown increased TH protein expression in the locus coeruleus of patients with major depression (Zhu et al, 1999 ) and increased VMAT2 binding in both the thalamus and ventral midbrain of bipolar disorder patients (Zubieta et al, 2001).

The finding of increased dopamine release in the PFC suggests a causal link between the neuroendocrine abnormalities observed in mood disorders, and some of the cognitive symptoms of these conditions: the PFC plays a key role in cognitive functions including working memory, selective attention, goal directed behavior, and behavioral inhibition (Dalley et al, 2008; Nagahama et al, 1996; Wager and Smith, 2003) with PFC dopaminergic neurotransmission strongly influencing these functions (Arnsten and $\mathrm{Li}$, 2005; Dalley et al, 2008; Sawaguchi and Goldman-Rakic, 1994). In this context, our data can be seen to offer further support to the targeting of dopaminergic and glucocorticoid signalling pathways for the treatment of affective disorders.

\section{ACKNOWLEDGEMENTS}

This study was supported by funds from the Stanley Medical Research Institute.

\section{DISCLOSURE/CONFLICT OF INTEREST}

SEG, AHY and CDI have been the recipients of unrestricted research grant funding from Organon Laboratories and are co-inventors on a patent application relating to the therapeutic use of glucocorticoid receptor antagonists. The remaining authors have no conflict of interest.

\section{REFERENCES}

Ago Y, Nakamura S, Baba A, Matsuda T (2005). Sulpiride in combination with fluvoxamine increases in vivo dopamine release selectively in rat prefrontal cortex. Neuropsychopharmacology 30: 43-51. 
Akesode A, Hendler N, Kowarski A (1976). A 24-hr monitoring of the integrated plasma concentration of aldosterone and cortisol in manic patients. Psychoneuroendocrinology 1: 419-426.

Anton R, Kordower JH, Maidment NT, Manaster JS, Kane DJ, Rabizadeh S et al. (1994). Neural-targeted gene therapy for rodent and primate hemiparkinsonism. Exp Neurol 127: 207-218.

Arnsten AF (1997). Catecholamine regulation of the prefrontal cortex. J Psychopharmacol 11: 151-162.

Arnsten AF, Li BM (2005). Neurobiology of executive functions: catecholamine influences on prefrontal cortical functions. Biol Psychiatry 57: 1377-1384.

Baetge EE, Kaplan BB, Reis DJ, Joh TH (1981). Translation of tyrosine hydroxylase from poly(A)-mRNA in pheochromocytoma cells is enhanced by dexamethasone. Proc Natl Acad Sci USA 78: 1269-1273.

Barrot M, Abrous DN, Marinelli M, Rouge-Pont F, Le Moal M, Piazza PV (2001). Influence of glucocorticoids on dopaminergic transmission in the rat dorsolateral striatum. Eur J Neurosci 13: 812-818

Barrot M, Marinelli M, Abrous DN, Rouge-Pont F, Le Moal M, Piazza PV (2000). The dopaminergic hyper-responsiveness of the shell of the nucleus accumbens is hormone-dependent. Eur J Neurosci 12: 973-979.

Bean AJ, Roth RH (1991). Extracellular dopamine and neurotensin in rat prefrontal cortex in vivo: effects of median forebrain bundle stimulation frequency, stimulation pattern, and dopamine autoreceptors. J Neurosci 11: 2694-2702.

Beauregard M, Levesque J, Bourgouin P (2001). Neural correlates of conscious self-regulation of emotion. J Neurosci 21: RC165.

Biron D, Dauphin C, Di Paolo T (1992). Effects of adrenalectomy and glucocorticoids on rat brain dopamine receptors. Neuroendocrinology 55: 468-476.

Blumberg HP, Leung HC, Skudlarski P, Lacadie CM, Fredericks CA, Harris BC et al. (2003). A functional magnetic resonance imaging study of bipolar disorder: state- and trait-related dysfunction in ventral prefrontal cortices. Arch Gen Psychiatry 60: 601-609.

Brambilla P, Barale F, Soares JC (2003). Atypical antipsychotics and mood stabilization in bipolar disorder. Psychopharmacology (Berl) 166: 315-332.

Brodkin ES, Kosten TA, Haile CN, Heninger GR, Carlezon Jr WA, Jatlow $\mathrm{P}$ et al. (1999). Dark agouti and Fischer 344 rats: differential behavioral responses to morphine and biochemical differences in the ventral tegmental area. Neuroscience 88: $1307-1315$

Brook NM, Cookson IB (1978). Bromocriptine-induced mania? Br Med J 1: 790.

Cervantes P, Gelber S, Kin FN, Nair VN, Schwartz G (2001). Circadian secretion of cortisol in bipolar disorder. J Psychiatry Neurosci 26: 411-416.

Czyrak A, Mackowiak M, Chocyk A, Fijal K, Wedzony K (2003). Role of glucocorticoids in the regulation of dopaminergic neurotransmission. Pol J Pharmacol 55: 667-674.

Dalley JW, Cardinal RN, Robbins TW (2004). Prefrontal executive and cognitive functions in rodents: neural and neurochemical substrates. Neurosci Biobehav Rev 28: 771-784.

Dalley JW, Mar AC, Economidou D, Robbins TW (2008). Neurobehavioral mechanisms of impulsivity: fronto-striatal systems and functional neurochemistry. Pharmacol Biochem Behav 90: 250-260.

DeBattista C (2005). Executive dysfunction in major depressive disorder. Expert Rev Neurother 5: 79-83.

Deuschle M, Schweiger U, Weber B, Gotthardt U, Korner A, Schmider J et al. (1997). Diurnal activity and pulsatility of the hypothalamus-pituitary-adrenal system in male depressed patients and healthy controls. J Clin Endocrinol Metab 82: 234-238.
Devoto P, Flore G, Pani L, Gessa GL (2001). Evidence for co-release of noradrenaline and dopamine from noradrenergic neurons in the cerebral cortex. Mol Psychiatry 6: 657-664.

Fairchild G, Leitch MM, Ingram CD (2003). Acute and chronic effects of corticosterone on 5-HT1A receptor-mediated autoinhibition in the rat dorsal raphe nucleus. Neuropharmacology 45: 925-934.

Faunt JE, Crocker AD (1988). Adrenocortical hormone status affects responses to dopamine receptor agonists. Eur J Pharmacol 152: 255-261.

Faunt JE, Crocker AD (1989). Effects of adrenalectomy on responses mediated by dopamine D-1 and D-2 receptors. Eur J Pharmacol 162: 237-244.

Fernandez Espejo E (2003). Prefrontocortical dopamine loss in rats delays long-term extinction of contextual conditioned fear, and reduces social interaction without affecting short-term social interaction memory. Neuropsychopharmacology 28: 490-498.

Ferrie LJ (2004). The effect of chronic lithium treatment and withdrawal from chronic lithium treatment on mesocorticolimbic dopamine function. PhD thesis Newcastle University, pp 129-134.

Floresco SB, Magyar O (2006). Mesocortical dopamine modulation of executive functions: beyond working memory. Psychopharmacology (Berl) 188: 567-585.

Gerner RH, Post RM, Bunney Jr WE (1976). A dopaminergic mechanism in mania. Am J Psychiatry 133: 1177-1180.

Gessa GL, Devoto P, Diana M, Flore G, Melis M, Pistis M (2000). Dissociation of haloperidol, clozapine, and olanzapine effects on electrical activity of mesocortical dopamine neurons and dopamine release in the prefrontal cortex. Neuropsychopharmacology 22: 642-649.

Hagerty T, Morgan WW, Elango N, Strong R (2001). Identification of a glucocorticoid-responsive element in the promoter region of the mouse tyrosine hydroxylase gene. J Neurochem 76: 825-834.

Haile CN, Hiroi N, Nestler EJ, Kosten TA (2001). Differential behavioral responses to cocaine are associated with dynamics of mesolimbic dopamine proteins in Lewis and Fischer 344 rats. Synapse 41: 179-190.

Kaiser S, Unger J, Kiefer M, Markela J, Mundt C, Weisbrod M (2003). Executive control deficit in depression: event-related potentials in a Go/Nogo task. Psychiatry Res 122: 169-184.

Kapur S, Mamo D (2003). Half a century of antipsychotics and still a central role for dopamine D2 receptors. Prog Neuropsychopharmacol Biol Psychiatry 27: 1081-1090.

Kemperman CJ, Zwanikken GJ (1987). Psychiatric side effects of bromocriptine therapy for postpartum galactorrhoea. $J R$ Soc Med 80: 387-388.

Kilty JE, Lorang D, Amara SG (1991). Cloning and expression of a cocaine-sensitive rat dopamine transporter. Science 254: 578-579.

Kolur US, Reddy YC, John JP, Kandavel T, Jain S (2006). Sustained attention and executive functions in euthymic young people with bipolar disorder. Br J Psychiatry 189: 453-458.

Kumai T, Asoh K, Tateishi T, Tanaka M, Watanabe M, Shimizu H et al. (2000). Involvement of tyrosine hydroxylase up regulation in dexamethasone-induced hypertension of rats. Life Sci 67: 1993-1999.

Lampe IK, Sitskoorn MM, Heeren TJ (2004). Effects of recurrent major depressive disorder on behavior and cognitive function in female depressed patients. Psychiatry Res 125: 73-79.

Levesque J, Eugene F, Joanette Y, Paquette V, Mensour B, Beaudoin G et al. (2003). Neural circuitry underlying voluntary suppression of sadness. Biol Psychiatry 53: 502-510.

Linkowski P (2003). Neuroendocrine profiles in mood disorders. Int J Neuropsychopharmacol 6: 191-197.

Linkowski P, Kerkhofs M, Van Onderbergen A, Hubain P, Copinschi G, L'Hermite-Baleriaux $M$ et al. (1994). The 24-hour profiles of cortisol, prolactin, and growth hormone secretion in mania. Arch Gen Psychiatry 51: 616-624. 
Malhi GS, Ivanovski B, Hadzi-Pavlovic D, Mitchell PB, Vieta E, Sachdev P (2007). Neuropsychological deficits and functional impairment in bipolar depression, hypomania and euthymia. Bipolar Disord 9: 114-125.

Martinez-Aran A, Vieta E, Reinares M, Colom F, Torrent C, Sanchez-Moreno J et al. (2004). Cognitive function across manic or hypomanic, depressed, and euthymic states in bipolar disorder. Am J Psychiatry 161: 262-270.

McLean A, Rubinsztein JS, Robbins TW, Sahakian BJ (2004). The effects of tyrosine depletion in normal healthy volunteers: implications for unipolar depression. Psychopharmacology (Berl) 171: 286-297.

McTavish SF, McPherson MH, Harmer CJ, Clark L, Sharp T, Goodwin GM et al. (2001). Antidopaminergic effects of dietary tyrosine depletion in healthy subjects and patients with manic illness. Br J Psychiatry 179: 356-360.

Mizoguchi K, Ishige A, Takeda S, Aburada M, Tabira T (2004). Endogenous glucocorticoids are essential for maintaining prefrontal cortical cognitive function. $J$ Neurosci 24: 5492-5499.

Moghaddam B, Bunney BS (1990). Acute effects of typical and atypical antipsychotic drugs on the release of dopamine from prefrontal cortex, nucleus accumbens, and striatum of the rat: an in vivo microdialysis study. J Neurochem 54: 1755-1760.

Monsma Jr FJ, McVittie LD, Gerfen CR, Mahan LC, Sibley DR (1989). Multiple D2 dopamine receptors produced by alternative RNA splicing. Nature 342: 926-929.

Morgan MA, Schulkin J, LeDoux JE (2003). Ventral medial prefrontal cortex and emotional perseveration: the memory for prior extinction training. Behav Brain Res 146: 121-130.

Morrow BA, Elsworth JD, Rasmusson AM, Roth RH (1999). The role of mesoprefrontal dopamine neurons in the acquisition and expression of conditioned fear in the rat. Neuroscience 92: 553-564.

Nagahama Y, Fukuyama H, Yamauchi H, Matsuzaki S, Konishi J, Shibasaki $\mathrm{H}$ et al. (1996). Cerebral activation during performance of a card sorting test. Brain 119: 1667-1675.

Ochsner KN, Ray RD, Cooper JC, Robertson ER, Chopra S, Gabrieli JD et al. (2004). For better or for worse: neural systems supporting the cognitive down- and up-regulation of negative emotion. Neuroimage 23: 483-499.

Ohira H, Nomura M, Ichikawa N, Isowa T, Iidaka T, Sato A et al. (2006). Association of neural and physiological responses during voluntary emotion suppression. Neuroimage 29: 721-733.

Ortiz J, DeCaprio JL, Kosten TA, Nestler EJ (1995a). Strainselective effects of corticosterone on locomotor sensitization to cocaine and on levels of tyrosine hydroxylase and glucocorticoid receptor in the ventral tegmental area. Neuroscience 67: 383-397.

Ortiz J, Fitzgerald LW, Charlton M, Lane S, Trevisan L, Guitart X et al. (1995b). Biochemical actions of chronic ethanol exposure in the mesolimbic dopamine system. Synapse 21: 289-298.

Piazza PV, Barrot M, Rouge-Pont F, Marinelli M, Maccari S, Abrous DN et al. (1996). Suppression of glucocorticoid secretion and antipsychotic drugs have similar effects on the mesolimbic dopaminergic transmission. Proc Natl Acad Sci USA 93: $15445-15450$

Porter RJ, Bourke C, Gallagher P (2007). Neuropsychological impairment in major depression: its nature, origin and clinical significance. Aust N Z J Psychiatry 41: 115-128.

Pothos EN, Larsen KE, Krantz DE, Liu Y, Haycock JW, Setlik W et al. (2000). Synaptic vesicle transporter expression regulates vesicle phenotype and quantal size. J Neurosci 20: 7297-7306.

Quraishi S, Frangou S (2002). Neuropsychology of bipolar disorder: a review. J Affect Disord 72: 209-226.

Robbins TW (2005). Chemistry of the mind: neurochemical modulation of prefrontal cortical function. J Comp Neurol 493: $140-146$
Robinson JL, Monkul ES, Tordesillas-Gutierrez D, Franklin C, Bearden CE, Fox PT et al. (2008). Fronto-limbic circuitry in euthymic bipolar disorder: evidence for prefrontal hyperactivation. Psychiatry Res 164: 106-113.

Rusnak M, Kvetnansky R, Jelokova J, Palkovits M (2001). Effect of novel stressors on gene expression of tyrosine hydroxylase and monoamine transporters in brainstem noradrenergic neurons of long-term repeatedly immobilized rats. Brain Res 899: 20-35.

Sachar EJ (1975). Twenty-four-hour cortisol secretory patterns in depressed and manic patients. Prog Brain Res 42: 81-91.

Savitz J, Solms M, Ramesar R (2005). Neuropsychological dysfunction in bipolar affective disorder: a critical opinion. Bipolar Disord 7: 216-235.

Sawaguchi T, Goldman-Rakic PS (1994). The role of D1-dopamine receptor in working memory: local injections of dopamine antagonists into the prefrontal cortex of rhesus monkeys performing an oculomotor delayed-response task. J Neurophysiol 71: 515-528.

Schatzberg AF, Rothschild AJ, Langlais PJ, Bird ED, Cole JO (1985). A corticosteroid/dopamine hypothesis for psychotic depression and related states. J Psychiatr Res 19: 57-64.

Schwartz K, Yadid G, Weizman A, Rehavi M (2003). Decreased limbic vesicular monoamine transporter 2 in a genetic rat model of depression. Brain Res 965: 174-179.

Serova L, Sabban EL, Zangen A, Overstreet DH, Yadid G (1998). Altered gene expression for catecholamine biosynthetic enzymes and stress response in rat genetic model of depression. Brain Res Mol Brain Res 63: 133-138.

Shoaib M, Shippenberg TS (1996). Adrenalectomy attenuates nicotine-induced dopamine release and locomotor activity in rats. Psychopharmacology (Berl) 128: 343-350.

Stephan FK, Zucker I (1972). Circadian rhythms in drinking behavior and locomotor activity of rats are eliminated by hypothalamic lesions. Proc Natl Acad Sci USA 69: 1583-1586.

Surja AA, Tamas RL, El-Mallakh RS (2006). Antipsychotic medications in the treatment of bipolar disorder. Curr Drug Targets 7: 1217-1224.

Tanganelli S, Fuxe K, von Euler G, Eneroth P, Agnati LF, Ungerstedt U (1990). Changes in pituitary-adrenal activity affect the apomorphine- and cholecystokinin-8-induced changes in striatal dopamine release using microdialysis. J Neural Transm Gen Sect 81: 183-194.

Tank AW, Curella P, Ham L (1986). Induction of mRNA for tyrosine hydroxylase by cyclic AMP and glucocorticoids in a rat pheochromocytoma cell line: evidence for the regulation of tyrosine hydroxylase synthesis by multiple mechanisms in cells exposed to elevated levels of both inducing agents. Mol Pharmacol 30: 497-503.

Thompson JM, Gallagher P, Hughes JH, Watson S, Gray JM, Ferrier IN et al. (2005). Neurocognitive impairment in euthymic patients with bipolar affective disorder. Br J Psychiatry 186: 32-40.

Urry HL, van Reekum CM, Johnstone T, Kalin NH, Thurow ME, Schaefer HS et al. (2006). Amygdala and ventromedial prefrontal cortex are inversely coupled during regulation of negative affect and predict the diurnal pattern of cortisol secretion among older adults. J Neurosci 26: 4415-4425.

Van Kammen DP, Murphy DL (1975). Attenuation of the euphoriant and activating effects of D- and L-amphetamine by lithium carbonate treatment. Psychopharmacologia 44: 215-224.

Vlissides DN, Gill D, Castelow J (1978). Bromocriptine-induced mania? $\mathrm{Br}$ Med J 1: 510.

Wager TD, Smith EE (2003). Neuroimaging studies of working memory: a meta-analysis. Cogn Affect Behav Neurosci 3: 255-274.

Wijkstra J, Lijmer J, Balk FJ, Geddes JR, Nolen WA (2006). Pharmacological treatment for unipolar psychotic depression: 
Glucocorticoid Diurnal Rhythm and Prefrontocortical Dopamine GO Minton et al

systematic review and meta-analysis. $\mathrm{Br} J$ Psychiatry 188: 410-415.

Wilson JM, Sanyal S, Van Tol HH (1998). Dopamine D2 and D4 receptor ligands: relation to antipsychotic action. Eur J Pharmacol 351: 273-286.

Windle RJ, Wood SA, Shanks N, Lightman SL, Ingram CD (1998). Ultradian rhythm of basal corticosterone release in the female rat: dynamic interaction with the response to acute stress. Endocrinology 139: 443-450.

Wong ML, Kling MA, Munson PJ, Listwak S, Licinio J, Prolo P et al. (2000). Pronounced and sustained central hypernoradrenergic function in major depression with melancholic features: relation to hypercortisolism and corticotropin-releasing hormone. Proc Natl Acad Sci USA 97: 325-330.
Yehuda R, Teicher MH, Trestman RL, Levengood RA, Siever LJ (1996). Cortisol regulation in posttraumatic stress disorder and major depression: a chronobiological analysis. Biol Psychiatry 40: 79-88.

Zhu MY, Klimek V, Dilley GE, Haycock JW, Stockmeier C, Overholser JC et al. (1999). Elevated levels of tyrosine hydroxylase in the locus coeruleus in major depression. Biol Psychiatry 46: 1275-1286.

Zubieta JK, Taylor SF, Huguelet P, Koeppe RA, Kilbourn MR, Frey KA (2001). Vesicular monoamine transporter concentrations in bipolar disorder type I, schizophrenia, and healthy subjects. Biol Psychiatry 49: $110-116$.

Zucker M, Weizman A, Rehavi M (2005). Repeated swim stress leads to down-regulation of vesicular monoamine transporter 2 in rat brain nucleus accumbens and striatum. Eur Neuropsychopharmacol 15: 199-201. 